\title{
Correction to: Characterizing the roles of bots on Twitter during the COVID-19 infodemic
}

\author{
Wentao Xu ${ }^{1}$ (D) Kazutoshi Sasahara ${ }^{2}$
}

Published online: 2 September 2021

(c) Springer Nature Singapore Pte Ltd. 2021

\section{Correction to: Journal of Computational Social Science https://doi.org/10.1007/s42001-021-00139-3}

Acknowledgement section was missing from this article and should have read as:

This study was supported by JST CREST grant no. JPMJCR20D3, and JSPS/ MEXT KAKENHI grant no. JP19H04217 and JP17H06383 in \#4903.

Publisher's Note Springer Nature remains neutral with regard to jurisdictional claims in published maps and institutional affiliations.

The original article can be found online at https://doi.org/10.1007/s42001-021-00139-3.

\section{Wentao Xu}

myrainbowandsky@gmail.com

1 Graduate School of Informatics, Nagoya University, Nagoya, Japan

2 School of Environment and Society, Tokyo Institute of Technology, Tokyo, Japan 